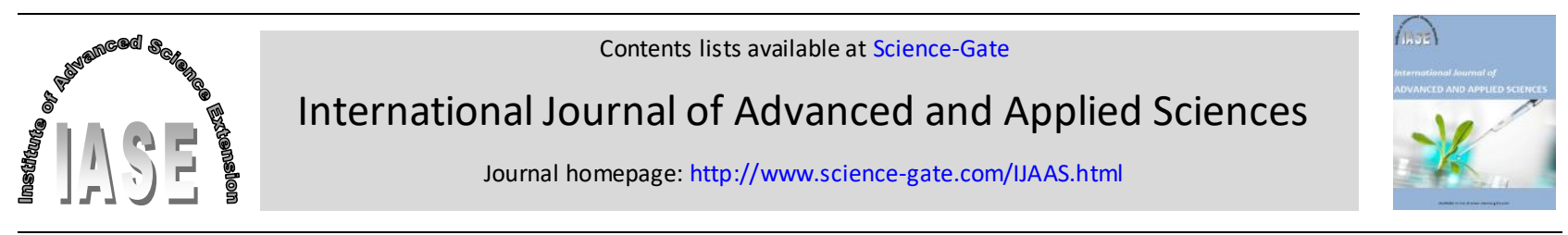

\title{
In vitro and in vivo hypoglycemic and colorimetric determination of glucose concentration of the different solvent extracts of Crescentia cujete Linn. fruit
}

\author{
Merell P. Billacura ${ }^{1,2}$ * , Ian Christopher T. Alansado ${ }^{1}$ \\ ${ }^{1}$ Chemistry Department, College of Natural Sciences and Mathematics, Mindanao State University-Main Campus, Marawi City, \\ Lanao del Sur 9200, Philippines \\ 2Mamitua Saber Research and Technology Center, Mindanao State University-Main Campus, Marawi City, Lanao del Sur 9200, \\ Philippines
}

\section{ART ICLE INFO}

\section{Article history:}

Received 18 February 2017

Received in revised form

15 April 2017

Accepted 17 April 2017

\section{Keywords:}

Blood glucose level

$\alpha$-Amylase

Metformin

Alloxan

\begin{abstract}
A B S T R A C T
In this study, Crescentia cujete Linn. fruit was extracted using 95\% ethanol and was concentrated in vacuo. The crude ethanolic extract (CEE) was then subjected to solvent partitioning using hexane and water. Fresh (FE) and decocted (DE) extracts were also prepared by $\mathrm{m} / \mathrm{v}$ ratio of sample:water. Among the plants samples in vitro hypoglycemic assay, 10000ppm hexane extract possessed the highest ability to inhibit (55.21\%) the activity of alphaamylase. Also, 10000ppm AE and CEE exhibited 32.87\% and 32.64\% inhibition, respectively. FE, DE, HE, AE and CEE were administered to the 24hour starved Mus musculus via oral gavage for eight consecutive days. The initial blood glucose level (BGL) of the test organisms was recorder and determined using one-touch glucometer. Twenty four hours after the eightday treatment, the blood glucose level was determined. In vivo hypoglycemic assay revealed positive BGL lowering in the FE, 10000ppm of $\mathrm{HE}, \mathrm{AE}$ and CEE upon comparison to the inducer, Alloxan. Protective potential assay also revealed significant lowering of BGL in the previously mentioned extracts with the addition of 1:1 m/v decocted and 5000ppm CEE. Moreover, Alloxan group was monitored for five days after its administration on the third day thus proving Alloxan's degradation. Colorimetric determination of glucose concentration in the plant sample was performed and it shows the increase in sample extract concentration is proportional to the amount of glucose in it. The pure decoction $4: 0 \mathrm{~m} / \mathrm{v}$ ratio revealed the highest glucose concentration (453.30ppm), while the $100 \mathrm{ppm}$ of CEE has the lowest glucose content (55.66ppm). The extracts of Crescentia cujete Linn. reveals hypoglycemic potential and its utilization before the occurrence of the metabolic disorder diabetes mellitus can help in regulating BGL in the blood.
\end{abstract}

(C) 2017 The Authors. Published by IASE. This is an open access article under the CC BY-NC-ND license (http://creativecommons.org/licenses/by-nc-nd/4.0/).

\section{Introduction}

In the beginning, humanity was able to thrive with just an abundance of plants and animals in the environment to depend on. The world itself is changing and not to mention the birth of diseases that became man's rival for survival. These diseases may be hereditary and can be acquired during a person's lifestyle.

According to the International Diabetes Federation (IDF, 2013), diabetes is a substantial and

\footnotetext{
* Corresponding Author.

Email Address: merelljohn@gmail.com (M. P. Billacura) https://doi.org/10.21833/ijaas.2017.07.005

2313-626X/C 2017 The Authors. Published by IASE

This is an open access article under the CC BY-NC-ND license

(http://creativecommons.org/licenses/by-nc-nd/4.0/)
}

a growing health problem. Diabetes mellitus is one of the leading causes of death in the United States and propagates gradually worldwide (Honeycutt et al., 2003). It is a serious chronic metabolic disorder and an important modifiable risk factor for cardiovascular diseases (Yusuf et al., 2004). It is reported to affect 170 million people around the globe and is foreseen to affect over 365 million people come 2030 (Wild et al., 2004).

According to the World Health Organization's (WHO, 2014) article titled Global status report on non-communicable diseases, the prevalence of diabetes has been increasing rapidly over the last decade and at present time the estimated global prevalence is $9 \%$. The burden of ill health due to diabetes has also been increasing, primarily in developing world. In 2014, diabetes caused 1.5 
million deaths worldwide and more than $80 \%$ of these deaths occurred in low and middle-income countries according to WHO's Global Health Estimates: Deaths by Cause, Age and Sex and Country article in 2014.

Traditional insulin replacement therapy is excruciatingly painful and is time consuming. Hovorka et al. (2013) stated that microcomputercontrolled closed loop insulin delivery systems are being developed. Despite this one of the many methods to improve a person's glucose control, it doesn't boast of its cost and maintenance. Not to mention are the probable inflammation and scarring (Xu et al., 2004). Thus, this demands for the pursuit of suitable hypoglycemic agents with more potential, readily available, less side effects and most importantly, low cost. The use of medicinal plants as a source for aid from illness can be traced back over five millennia to written documents of the early culture in China, India and the Near east, but it is, without a doubt, an art as old as mankind (Ekta, 2012). Medicinal plants are often considered to be less toxic and are free from side effects compared to synthetic ones. Plant-based medicines as an alternative to expensive synthetic ones enjoy increased therapeutic market share due to their mild action and fewer adverse effects. WHO (2014) has also recommended that the use of medicinal plants should be encouraged, especially in countries where conventional treatment of diabetes seems to be insufficient (Santhakumari et al., 2006).

Medicinal plants play a key role in health care with about $80 \%$ of the world's populations relying on the use of traditional medicine which is predominantly based on plants (Maher et al., 2000).

This study generally aimed to determine the hypoglycemic and protective potentials of the fresh, decocted, hexane, aqueous and crude ethanolic extracts from the Crescentia cujete Linn. fruit using in vitro (alpha-amylase inhibition activity) and in vivo screening method (utilizing Mus musculus as test organism) and the glucose concentration of the extracts being used.

\section{Preparation of fresh fruit extract and decoction}

Crescentia cujete Linn. fruit was collected from Brgy. Baganian, Tabina, Zamboanga del Sur $\left(07 \div 28^{\circ} \mathrm{N}, 123^{\circ} 25^{\circ} \mathrm{E}\right)$. The fruit was washed and then cut into half. The whole fruit material was scraped and was placed in a $1000 \mathrm{~mL}$ beaker. For the fresh fruit extract, the fruit material was scraped and the juice was filtered and residue was discarded. The ratio of $4: 0,1: 1$ and $1: 3(\mathrm{~m} / \mathrm{v}$ ratio of the sample: water) as decoction were prepared by boiling for 20 minutes. The resulting mixture was then filtered and residue was discarded.

\subsection{Preparation of crude ethanolic extract}

For convenience in soaking the fruit sample, it was weighed (about 300g) into $1000 \mathrm{~mL}$ Erlenmeyer flask. It was then treated with $95 \%$ ethanol. It was made sure that the whole sample was submerged in ethanol. The flask was then stoppered using aluminum foil, secured with a rubber band. The entire soaking process lasted for 72 hours with stirring every after 24 hours. Afterwards, the mixture was filtered using a filter paper, a funnel and a funnel holder. The fruit residue was discarded. The filtrate was stored in a beaker tightly covered with an aluminum foil stopper supported with a rubber band and kept in a refrigerator.

\subsection{Solvent partitioning}

Fifty milliliter of the crude ethanolic extract (CEE) was measured and transferred into a $250 \mathrm{~mL}$ separatory funnel. Fifty milliliter of hexane was then added to the same separatory funnel. The mixture was shaken with frequent opening of the cartridge to expel evolved gases. Next, the solution was allowed to stand for several minutes until the complete separation of the mixture was observed. The bottom layer was the aqueous layer while the top layer was the organic layer. The aqueous layer was first drained, then the organic layer was placed in a separate beaker labeled with hexane extract (HE). The procedure was repeated for the remaining volume of crude ethanolic extracts until the hexane layer becomes colorless. The aqueous portion was partitioned again using ethyl acetate carrying out the same procedure with hexane. The aqueous layer was drained first followed by the organic layer which was transferred in a clean beaker labeled with ethyl acetate extract (EAE). This was not used due to insufficient amount collected. The entire aqueous portion was placed in a separate beaker labeled with (AE). The obtained fraction from the partitioning process was then concentrated in vacuo using the rotary evaporator.

\subsection{Hypoglycemic assay}

The test for the hypoglycemic potential of Crescentia cujete Linn. fruit was divided into two parts: in vivo and in vitro screening methods. The tests made use of the FE, DE, HE, AE and CEE.

\subsection{In vitro screening method}

Each extract of the Crescentia cujete Linn. fruit was assessed for in vitro hypoglycemic activity by the alpha-amylase inhibition using the procedure described by Worthington (1993).

\section{5. $\alpha$-Amylase inhibition activity}

Each extract $(100 \mu \mathrm{L})$ was mixed with $100 \mu \mathrm{L}$ of $0.02 \mathrm{~mol} / \mathrm{L}$ sodium phosphate buffer ( $\mathrm{pH} 6.9$ ) and $100 \mu \mathrm{L} \alpha$-amylase solution (4.5units $/ \mathrm{mL} / \mathrm{minute}$ ) and pre-incubated at $25^{\circ} \mathrm{C}$ for 10 minutes. Then, $100 \mu \mathrm{L}$ of $1 \%$ freshly prepared starch solution was added and was incubated again at $25^{\circ} \mathrm{C}$ for 30 
minutes and the reaction was stopped by the addition of $1.0 \mathrm{~mL}$ dinitrosalicylic reagent. The test tube was then incubated in a boiling water bath for 5 minutes and then cooled to room temperature. The reaction mixture was diluted 10 -fold times with distilled water and the absorbance was measured at $540 \mathrm{~nm}$. The readings were compared with the control (the sample was replaced by buffer) and $\alpha$ amylase inhibition activity (\%) was calculated.

\subsection{In vivo screening method}

The in vivo test utilizes the use of Mus musculus as test organism. Various extracts such as 5000ppm and $10000 \mathrm{ppm}$ each of hexane extract, aqueous extract, and crude ethanolic extract were used. Also, it was administered with fresh extract alongside decocted 4:0 and 1:1 (m/v ratio of the sample:water) extract.

\subsection{Test organism}

Sixty nine albino mice were placed in a cage and acclimatized for a week with a 24-hour dark-light cycle at a normal weather condition in Barrio Salam, Mindanao State University, Marawi City, Lanao del Sur, Philippines. They were given unlimited access to water and fed twice a day. Before introducing the solutions, the Mus musculus were fasted overnight with an unlimited access to water. The body weight of the Mus musculus was determined using a top loading balance. During the treatment process, the test organisms were divided into twenty three groups with three albino mice in each group and treated as follows.

- Group 1 received distilled water for 8 days

- Group 2 received distilled water for 5 days after treatment of Alloxan for 3 days

- Group 3 received Alloxan for 3 days after treatment of distilled water for 3 days

- Group 4 received Metformin for 5 days after treatment of Alloxan for 3 days

- Group 5 received Alloxan for 3 days after treatment of Metformin for 5 days

- Group 6 received FE for 5 days after treatment of Alloxan for 3 days

- Group 7 received Alloxan for 3 days after treatment of FE for 5 days

- Group 8 received DE 4:0m/v for 5 days after treatment of Alloxan for 3 days

- Group 9 received Alloxan for 3 days after treatment of DE $4: 0 \mathrm{~m} / \mathrm{v}$ for 5 days

- Group 10 received DE $1: 1 \mathrm{~m} / \mathrm{v}$ for 5 days after treatment of Alloxan for 3 days

- Group 11 received Alloxan for 3 days after treatment of DE $1: 1 \mathrm{~m} / \mathrm{v}$ for 5 days

- Group 12 received 10000 ppm HE for 5 days after treatment of Alloxan for 3 days

- Group 13 received Alloxan for 3 days after treatment of 10000 ppm HE for 5 days
- Group 14 received 5000ppm HE for 5 days after treatment of Alloxan for 3 days

- Group 15 received Alloxan for 3 days after treatment of 5000ppm HE for 5 days

- Group 16 received 10000 ppm AE for 5 days after treatment of Alloxan for 3 days

- Group 17 received Alloxan for 3 days after treatment of $10000 \mathrm{ppm}$ AE for 5 days

- Group 18 received 5000ppm AE for 5 days after treatment of Alloxan for 3 days

- Group 19 received Alloxan for 3 days after treatment of 5000 ppm AE for 5 days

- Group 20 received 10000ppm CEE for 5 days after treatment of Alloxan for 3 days

- Group 21 received Alloxan for 3 days after treatment of 10000ppm CEE for 5 days

- Group 22 received 5000ppm CEE for 5 days after treatment of Alloxan for 3 days

- Group 23 received Alloxan for 3 days after treatment of 5000 ppm CEE for 5 days

All the solutions induced depend on the body weight of the Mus musculus. The dosage of the test samples were around $0.20 \mathrm{~mL} / 20 \mathrm{~g}$ body weight. For Alloxan (150mg/kg BW) and Metformin solution, 10000 ppm was used.

\subsection{Hypoglycemic and protective potential determination}

Blood analysis was done before and after eight days of treatment. Protective test was done by treating the mouse with the extracts prior to the administration of Alloxan. Blood glucose level of the Mus musculus was determined after 24 hours of the subsequent treatment period. Blood sampling was done by pricking the tail of the mouse then its blood glucose level was determined using one touch glucometer.

\subsection{Colorimetric determination of glucose concentration}

Three milliliters of the plant sample was added with $3 \mathrm{~mL}$ of 3,5-dinitrosalicylic acid reagent. The mixture was then heated at $90^{\circ} \mathrm{C}$ for $5-15$ minutes to develop a red-brown color. To stabilize the color, $1 \mathrm{~mL}$ of $40 \%$ potassium sodium tartrate solution was added and then cooled to room temperature in a water bath. The absorbance was recorded using a UV-Vis spectrophotometer at $575 \mathrm{~nm}$. The glucose concentrations of the samples were determined using the calibration curve obtained from the standard glucose samples.

\section{Results and Discussion}

\subsection{In vitro hypoglycemic activity}

Hypoglycemia is when blood sugar decreases to below normal levels. The most common cause of 
hypoglycemia is medications used to treat diabetes mellitus such as insulin (NIDDK, 2003).

The fresh, decocted 4:0,1:1 and 1:3 (m/v ratio of the sample: water) and different concentrations $(100,1000$ and $10000 \mathrm{ppm})$ of the various solvent extracts (hexane, aqueous and crude ethanolic) of Crescentia cujete Linn. fruit were assessed using in vitro hypoglycemic activity by alpha-amylase inhibition using the procedure described by Worthington (1993). The wavelength was set from 300 to $600 \mathrm{~nm}$ and scanning for the $K \max$ was determined.

The $\Lambda$ max for alpha-amylase inhibition activity was $428 \mathrm{~nm}$ and the absorbance range was 0.00 to 6.00. The absorbance of the control in the alpha- amylase inhibition activity was 4.4412. Table 1 summarizes the calculated percent (\%) inhibition of each extracts in the alpha-amylase inhibition assay. Percent inhibition of each assay was calculated using the formula below (Eq. 1):

\%inhibition $=\frac{A b_{\text {Scontrol }}-A b_{\text {Ssample }}}{A b_{\text {Scontrol }}}$

In Table 1, the fresh fruit extract shows a relatively low percent inhibition of $0.0068 \%$. Also, the three concentrations $4: 0,1: 1$ and $1: 3$ (m/v ratio of the sample: water) of the decocted samples depicted a low percent inhibitions of $0.0045 \%$, $0.0068 \%$ and $0.0090 \%$, respectively.

Table 1: Percent (\%) alpha-amylase inhibition of the three concentrations of the different solvent extracts, fresh and

\begin{tabular}{cccc}
\multicolumn{4}{c}{ decocted samples of Crescentia cujete Linn. fruit } \\
\hline Sample & Concentration & Absorbance (nm) & $\%$ inhibition \\
\hline Fresh sample & Fresh sample & 4.4409 & 0.0068 \\
& Decoction 4:0 & 4.4410 & 0.0045 \\
Decocted sample(m/v ratio of the sample: water) & Decoction 1:1 & 4.4409 & 0.0068 \\
& Decoction 1:3 & 4.4408 & 0.0090 \\
& $100 \mathrm{ppm}$ & 4.4407 & 0.0113 \\
Hexane extract & $1000 \mathrm{ppm}$ & 4.4401 & 0.0248 \\
& $10000 \mathrm{ppm}$ & 1.9891 & 55.2100 \\
& $100 \mathrm{ppm}$ & 4.4407 & 0.0113 \\
Aqueous extract & $1000 \mathrm{ppm}$ & 4.4402 & 0.0225 \\
& $10000 \mathrm{ppm}$ & 2.9812 & 32.8700 \\
& $100 \mathrm{ppm}$ & 4.4409 & 0.0068 \\
Crude ethanolic extract & $1000 \mathrm{ppm}$ & 4.4408 & 0.0090 \\
& $10000 \mathrm{ppm}$ & 2.9918 & 32.6400 \\
\hline
\end{tabular}

However, it can be inferred that upon dilution of the decocted fruit extract, there is a slight increase in activity towards alpha-amylase. The three concentrations of the hexane extract of 100-, 1000-, and $10000 \mathrm{ppm}$ exhibited 0.0113, 0.0248 and $55.2100 \%$ inhibition, respectively. It can be deduced that as the concentration increases, inhibition increases with concentration. It can also be observed that there is a relative increase in inhibition activity between 1000- and 10000ppm concentrations. 100-, $1000-$, and $10000 \mathrm{ppm}$ of aqueous extract gave $0.0013, \quad 0.0225$ and $32.8700 \%$ inhibition, respectively. Also, there is a relative difference between the 1000- and 10000ppm percent inhibition. 100, 1000 and $10000 \mathrm{ppm}$ of crude ethanolic extracts depicted 0.0068, 0.0090 and $32.6400 \%$ inhibition, respectively. Similar to the aqueous and hexane extracts, there is also a significant difference between 1000-10000 ppm \% inhibition.

\subsection{In vivo hypoglycemic activity}

Accounted to the diminished production of insulin, diabetes is a disorder of carbohydrate, fat and protein metabolism. In controlling hyperglycemia, most people use hydroglycemic drugs. The in vivo hypoglycemic activity utilized the fresh sample, decocted 4:0 and 1:1 (m/v ratio of the sample: water) and concentrations (5000 and $10000 \mathrm{ppm}$ ) from the hexane, aqueous and crude ethanolic extracts. The ethyl acetate extract was also not used due to its insufficient amount. Each group has three albino mice and their body weight was determined for the amount of sample to be induced during oral gavage $(0.20 \mathrm{~mL} / 20 \mathrm{~g} \mathrm{BW})$.

\subsection{Hypoglycemic activity of the various extracts}

Hypoglycemic activity was conducted by introducing fresh extract of Crescentia cujete Linn fruit. Another treatment groups were also administered with a $4: 0$ and $1: 1(\mathrm{~m} / \mathrm{v}$ ratio of the sample:water) decoction of the said sample. 5000 and $10000 \mathrm{ppm}$ of the hexane, aqueous and crude ethanolic extracts of Crescentia cujete Linn. were also administered. 10000ppm of Alloxan was administered for three days. After which, the respective extracts were given to the test organisms for five days.

Table 2 shows the hypoglycemic activity of the fresh and decocted extracts of Crescentia cujete Linn. fruit induced by oral gavage in Mus musculus before and after eight days of treatment. Twenty four hours after the last treatment, the blood glucose level (BGL) difference is computed by subtracting the BGL before treatment from the BGL after the treatment period. As shown in Table 2, Alloxan administration showed the largest mean difference $(37.33 \mathrm{mg} / \mathrm{dL})$ between the BGL before and after treatment. This just proves that Alloxan is effective in raising the blood glucose level of the Mus musculus. The distilled water (negative control) showed a slight mean increase in the BGL by $3.00 \mathrm{mg} / \mathrm{dL}$. Grp 4 (Metformin) being the positive control showed the smallest mean difference of $0.34 \mathrm{mg} / \mathrm{dL}$. It depicts 
that Metformin has been an effective agent in blood sugar lowering of the Mus musculus that the BGL before and after Alloxan administration is almost similar.

Table 2: Hypoglycemic activity of the fresh and decocted extracts of Crescentia cujete Linn. fruit by oral gavage in Mus musculus before and after treatment

\begin{tabular}{cccc}
\hline Grp & Mean BGL (mg/dL) before induction & Mean BGL (mg/dL) after induction & BGL Difference (mg/dL) \\
\hline 1 & 80.33 & 83.33 & $3.00^{\mathrm{C}}$ \\
2 & 75.00 & 112.33 & $37.33^{\mathrm{A}}$ \\
4 & 84.33 & 84.67 & $0.34^{\mathrm{D}}$ \\
6 & 87.00 & 115.00 & $28.00^{\mathrm{B}}$ \\
8 & 103.67 & 139.67 & $36.00^{\mathrm{A}}$ \\
10 & 114.67 & 151.00 & $36.33^{\mathrm{A}}$ \\
\hline Legend: Grp 1: Negative Control (distilled water) 2: (Alloxan + distilled water) 4: Positive Control (Alloxan+Metformin) 6: Alloxan+Fresh sample 8: Alloxan+4:0
\end{tabular}
decocted sample 10: Alloxan+1:1 decocted sample. Means having same letters have no significant difference at $\alpha=0.05$

Grp 6 (fresh sample) having a mean difference of $28.00 \mathrm{mg} / \mathrm{dL}$ is higher than that of Grp 4 (Metformin) which means that it is not as effective as the positive control in lowering down the BGL, but it is significantly lower than that of Grp 2 (Alloxan) which makes it a potential hypoglycemic agent. Grp 8 (4:0 $\mathrm{m} / \mathrm{v}$ ratio of the sample: water) decocted sample has a mean difference of $36.00 \mathrm{mg} / \mathrm{dL}$ which is also higher than that of Grp 4 (Metformin) and explains that it is not as effective as the positive control in lowering the BGL of Mus musculus. Upon comparison to Grp 2 (Alloxan), the relatively similar values attributes to inability of the decocted $(4: 0 \mathrm{~m} / \mathrm{v}$ ratio of the sample: water) sample to lower down the blood glucose level of Mus musculus. Grp 10 (1:1 m/v ratio of the sample: water) decocted sample has a mean difference of $36.33 \mathrm{mg} / \mathrm{dL}$ which is also higher than that of Grp 4 (Metformin) and explains that it is not also as effective as the positive control in lowering the BGL of Mus musculus. After comparison to Grp 2 (Alloxan), the relatively similar values also attributes to inability of the decocted $(1: 1 \mathrm{~m} / \mathrm{v}$ ratio of the sample:water) sample to lower down the BGL of Mus musculus. The fresh sample is more effective in lowering blood glucose level when compared to the $4: 0$ and $1: 1(\mathrm{~m} / \mathrm{v}$ ratio of the sample: water $)$ decocted samples that showed relatively similar activity.

In Table 3, Alloxan administration (Grp 2) showed the largest mean difference $(37.33 \mathrm{mg} / \mathrm{dL})$ between the BGL before and after treatment. The distilled water control showed a slight mean increase in the blood glucose level by $3.00 \mathrm{mg} / \mathrm{dL}$. Metformin, being the positive control showed the smallest mean difference of $0.34 \mathrm{mg} / \mathrm{dL}$. Grp 12 (10000ppm hexane extract) having a mean difference of $17.67 \mathrm{mg} / \mathrm{dL}$ is higher than that of Grp 4 (Metformin) which makes it not as effective as the positive control in lowering down the blood glucose level. However, it is lower than that of Grp 2 (Alloxan) which makes it a potential hypoglycemic agent. Grp 14 (5000ppm hexane extract) has a mean difference of $36.33 \mathrm{mg} / \mathrm{dL}$ which is also higher than Grp 4 (Metformin) and explains that it is not capable of lowering the blood glucose level of Mus musculus. Upon comparison to Grp 2 (Alloxan), the relatively similar values attributes to inability of the $5000 \mathrm{ppm}$ hexane extract sample to lower down the blood glucose level of Mus musculus. Ten thousand (10000) ppm hexane extract is more effective in lowering blood glucose level when compared to 5000ppm of the same extract which suggests that hypoglycemic activity of hexane extract is dose dependent.

Table 3: Hypoglycemic activity of the hexane extracts of Crescentia cujete Linn. fruit by oral gavage in Mus musculus before

\begin{tabular}{cccc}
\multicolumn{4}{c}{ and after treatment } \\
\hline Grp & Mean BGL (mg/dL) before induction & Mean BGL (mg/dL) after induction & BGL Difference (mg/dL) \\
\hline 1 & 80.33 & 83.33 & $3.00^{\mathrm{C}}$ \\
2 & 75.00 & 112.33 & $37.33^{\mathrm{A}}$ \\
4 & 84.33 & 84.67 & $0.34^{\mathrm{D}}$ \\
12 & 85.67 & 103.33 & $17.67^{\mathrm{B}}$ \\
14 & 74.00 & 110.33 & $36.33^{\mathrm{A}}$ \\
\hline
\end{tabular}

Legend: Grp 1: Negative Control (distilled water) 2: (Alloxan + distilled water) 4: Positive Control (Alloxan+Metformin) 12: Alloxan+10000ppm Hexane Extract 14: Alloxan+5000ppm Hexane Extract. Means having same letters have no significant difference at $\alpha=0.05$

As shown in Table 4, Alloxan administration (Grp 2) showed the largest mean difference $(37.33 \mathrm{mg} / \mathrm{dL})$ between the blood sugar level before and after treatment. This just proves that Alloxan is effective in raising the blood glucose level of the Mus musculus. The distilled water control showed a slight mean increase in the blood glucose level by $3.00 \mathrm{mg} / \mathrm{dL}$. Metformin (Grp 4) being the positive control showed the smallest mean difference of $0.34 \mathrm{mg} / \mathrm{dL}$. It depicts that Metformin has been an effective agent in blood sugar lowering of the Mus musculus that the BGL before and after Alloxan administration is almost similar. Grp 16 (10000ppm aqueous extract) having a mean difference of $21.33 \mathrm{mg} / \mathrm{dL}$ is higher than that of Grp 4 (Metformin) which depicts that it is not as effective as the positive control in lowering down the blood glucose level, but it is significantly lower than that of Grp 2 (Alloxan) which makes it a potential hypoglycemic agent. Grp 18 (5000ppm aqueous extract) having a mean difference of $32.33 \mathrm{mg} / \mathrm{dL}$ is higher than that of Grp 4 (Metformin) which makes it not as effective as the positive control in lowering down the blood glucose level of the test organism. 10000ppm aqueous extract is more effective in lowering blood glucose level when compared to 5000ppm of the same 
extract which suggests that the aqueous extract is dose-dependent.

In Table 5, Alloxan administration (Grp 2) showed the largest mean difference $(37.33 \mathrm{mg} / \mathrm{dL})$ between the blood sugar level before and after treatment. The distilled water control showed a slight mean increase in the blood glucose level by $3.00 \mathrm{mg} / \mathrm{dL}$. Metformin (Grp 4) being the positive control showed the slightest difference of $0.34 \mathrm{mg} / \mathrm{dL}$. Grp 20 (10000ppm crude ethanolic extract) having a mean difference of $26.67 \mathrm{mg} / \mathrm{dL}$ is higher than that of Grp 4 (Metformin) which makes it not as effective as the positive control in lowering down the blood glucose level. However, it is lower than that of Grp 2 (Alloxan) which makes it a potential hypoglycemic agent. Grp 22 (5000ppm crude ethanolic extract) has a mean difference of $31.00 \mathrm{mg} / \mathrm{dL}$ which is higher than that of Grp 4 (Metformin) which makes it not effective when compared to the positive control in lowering down the blood glucose level. However, its relative similar value when compared with Grp 2 (Alloxan) attributes to its inability as potent hypoglycemic agent. 10000 ppm crude ethanolic extract is more effective in lowering blood glucose level when compared to $5000 \mathrm{ppm}$ of the same extract which suggests that at higher concentration of the hexane extract, hypoglycemic activity is observable.

Table 4: Hypoglycemic activity of the aqueous extracts of Crescentia cujete Linn. fruit by oral gavage in Mus musculus before

\begin{tabular}{cccc} 
& \multicolumn{3}{c}{ and after treatment } \\
\hline Grp & Mean BGL (mg/dL) before induction & Mean BGL (mg/dL) after induction & BGL Difference (mg/dL) \\
\hline 1 & 80.33 & 83.33 & $3.00^{\mathrm{C}}$ \\
2 & 75.00 & 112.33 & $37.33^{\mathrm{A}}$ \\
4 & 84.33 & 91.67 & $0.34^{\mathrm{D}}$ \\
16 & 88.00 & 120.33 & $21.33^{\mathrm{B}}$ \\
18 & 88.00 & $32.33^{\mathrm{A}}$ \\
\hline \multicolumn{4}{c}{ Legend: Grp 1: Negative Control (distilled water) 2: (Alloxan + distilled water) 4: Alloxan+Metformin 16: Alloxan+10000ppm Aqueous Extract 18: }
\end{tabular}

Table 5: Hypoglycemic activity of the crude ethanolic extracts of Crescentia cujete Linn. fruit by oral gavage in Mus musculus

\begin{tabular}{cccc} 
& \multicolumn{2}{c}{ before and after treatment } \\
\hline Grp & Mean BGL (mg/dL) before induction & Mean BGL $(\mathrm{mg} / \mathrm{dL})$ after induction & BGL Difference (mg/dL) \\
\hline 1 & 80.33 & 83.33 & $3.00^{\mathrm{C}}$ \\
2 & 75.00 & 112.33 & $37.33^{\mathrm{A}}$ \\
4 & 84.33 & 84.67 & $0.34^{\mathrm{D}}$ \\
20 & 83.67 & 110.33 & $26.7^{\mathrm{B}}$ \\
22 & 83.33 & 114.33 & $31.00^{\mathrm{A}}$ \\
\hline
\end{tabular}

Legend: Grp 1: Negative Control (distilled water) 2: (Alloxan + distilled water) 4: Alloxan+Metformin, 20: Alloxan+10000ppm Crude Ethanolic Extract 22: Alloxan +5000 ppm Crude Ethanolic Extract. Means having same letters have no significant difference at $\alpha=0.05$

In general, according to Lima et al. (2001) in "Changes in Amylase Activity Starch and Sugar Contents in Mango Fruits Pulp", the contents of reducing sugar may be attributed to lower activities of amylase. The presence of reducing sugar in the extracts (10000ppm of hexane, aqueous and crude ethanolic) according to the phytochemical screening test of Billacura and Laciapag (2017) make them susceptible to inhibit the activity of alpha-amylase the greatest. Some possible reasons by which these plant extracts exert this kind of effect may be due to their action on carbohydrate-binding region of alpha-amylase enzymes that catalyze the hydrolysis of the internal alpha-1,4-glucosidic linkages in starch and other related polysaccharides have also been targeted for the suppression of postprandial hyperglycemia (Lima et al., 2001).

Reducing sugars are any sugar that is capable of acting as a reducing agent because it has free aldehyde or ketone group. Glucose, the most common example of reducing sugar has the ability to inhibit the action of alpha-amylase, an enzyme that is capable of breaking down long-chain carbohydrates that induces high concentration of glucose in the blood (Cornely and Pratt, 2012). The presence of reducing sugars in the fresh extract can be attributed to its ability to lower down blood glucose level in Mus musculus.

\subsection{Alloxan degradation}

Alloxan is a toxic glucose analogue, which selectively destroys insulin-producing cells in the pancreas when administered to rodents and many other animal species. This causes an insulindependent diabetes mellitus in mice with characteristics similar to Type 1 diabetes in humans (Lenzen, 2008).

The average values are based on three trials conducted. The degradation of 10000ppm Alloxan administered at $150 \mathrm{mg} / \mathrm{kg}$ BW to Grp 2 was recorded 24 hours after the third day of its administration. The blood glucose level was recorded for five days after 24-hour starvation of the Mus musculus. Table 6 depicts that for the 5-day recording of the blood glucose level, it can be deduced that the blood glucose level is decreasing from Day 4 up to Day 8. The mean BGL of Day 1 is significantly different from all the other days of test. Day 4 is significantly different from Days 7 and 8 yet similar to Days 5 and 6.

This is due to relatively high blood glucose level on the fifth and sixth day rather on the relatively-low BGL on Days 7 and 8. Day 5 is significantly different from Day 8 yet similar to Days 4,6 and 7. This is due to relatively high blood glucose level on the 5 th, 6 th and 7 th day rather on the relatively-low BGL on Day 8. Day 6 is significantly the same with all the other 
days since Day 6 is the mean of the test days. Day 7 is significantly similar with all other days but is significantly different with the fourth day. This is due to the very high blood glucose level in Day 4 when compared to Day 7. Lastly, Day 8 is significantly similar with the test days not later than Day 5. This may be attributed to the higher blood glucose level on the first two days of test for Alloxan degradation.

Table 6: Alloxan degradation after 3 day-administrations in Mus musculus

\begin{tabular}{cc}
\hline \multicolumn{2}{c}{ Mean BGL $(\mathrm{mg} / \mathrm{dL})$} \\
\hline 1 & $75.00^{\mathrm{D}}$ \\
4 & $159.00^{\mathrm{A}}$ \\
5 & $149.00^{\mathrm{A}}$ \\
6 & $134.33^{\mathrm{B}}$ \\
7 & $122.33^{\mathrm{B}}$ \\
8 & $112.33^{\mathrm{C}}$ \\
\hline Legend: Day 1: Before Alloxan was induced in Mus musculus Day 4, 5, 6, 7, 8: \\
After Alloxan induction and administration of distilled water. BGL-Blood \\
Glucose Level. Mean values are based on three trials
\end{tabular}

\subsection{Colorimetric determination of glucose concentration}

The colorimetric determination of glucose concentration of the fresh, decocted 4:0, 1:1 and 1:3 (m/v ratio of the sample: water) and the different concentrations $(100,1000$ and $10000 \mathrm{ppm})$ of the various solvent extracts (hexane, aqueous and crude ethanolic) of Crescentia cujete Linn. fruit was determined using the procedure by Miller (1959).

The free hydroxyl group at the anomeric center of glucose in this case is oxidized into carbonyl group. The method tests for the presence of free hydroxyl group, the so called reducing sugars. This involves the oxidation of the free hydroxyl group present in glucose. Simultaneously, 3, 5-dinitrosalicylic acid (DNSA) is reduced to 3-amino-5-nitrosalicylic acid under alkaline condition. It is good to note that one mole of sugar will react with one mole of 3,5dinitrosalicylic acid (Wang, 1999).

At $100 \mathrm{ppm}$, the observed absorbance was $0.605 \mathrm{~nm}$. For $200 \mathrm{ppm}, 1.591 \mathrm{~nm}$ absorbance was recorded. For 350- and 500ppm, 3.201 and 4.819nm absorbance were observed, respectively. As shown in Table 7 are the concentrations of glucose in the fresh, decocted 4:0, 1:1, 1:3 (m/v ratio of the sample: water) and the different concentrations (100, 1000 and $10000 \mathrm{ppm}$ ) of the various solvent extracts (hexane, aqueous and crude ethanolic) of Crescentia cujete Linn. fruit.

The slope of the calibration curve for the glucose standard is 0.0105 and the $y$-intercept is -0.4528

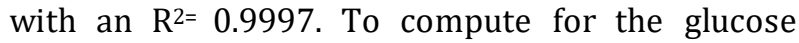
concentration present in the sample, we use the formula (Eq. 2),

Glucose concentration $(x)=\frac{\text { Absorbance }-(y-\text { intercept })}{\text { slope }}$

Table 7 shows that the fresh sample of Crescentia cujete Linn. fruit has an absorbance of $4.3066 \mathrm{~nm}$ with the corresponding value of 453.28ppm glucose. For the decocted samples of 4:0, 1:1 and 1:3 (m/v ratio of the sample: water), the recorded absorbance were $4.3068,4.3061$ and 4.3058 , respectively, with $453.30,453.23$ and $453.20 \mathrm{ppm}$ of glucose in them, respectively.

Table 7: Glucose concentrations of the different solvent extracts, fresh and decocted samples of Crescentia cujete Linn. fruit

\begin{tabular}{cccc}
\hline Sample & Concentration & Absorbance (nm) & Glucose concentration (ppm) \\
\hline Fresh sample & Fresh sample & 4.3066 & 453.28 \\
& Decoction 4:0 & 4.3068 & 453.30 \\
Decocted sample (m/v ratio of the sample:water) & Decoction 1:1 & 4.3061 & 453.23 \\
& Decoction 1:3 & 4.3058 & 453.20 \\
& $100 \mathrm{ppm}$ & 0.3705 & 78.41 \\
Hexane extract & $1000 \mathrm{ppm}$ & 0.4207 & 83.19 \\
& $10000 \mathrm{ppm}$ & 4.3062 & 453.24 \\
& $100 \mathrm{ppm}$ & 0.1723 & 59.53 \\
Aqueous extract & $1000 \mathrm{ppm}$ & 0.2045 & 62.60 \\
& $10000 \mathrm{ppm}$ & 3.4686 & 373.47 \\
& $100 \mathrm{ppm}$ & 0.1316 & 55.66 \\
Crude ethanolic extract & $1000 \mathrm{ppm}$ & 0.3790 & 79.22 \\
& $10000 \mathrm{ppm}$ & 4.3067 & 453.29 \\
\hline
\end{tabular}

It can be observed in the case of the three solvent extracts that as concentration increases, the concentration of glucose also increases. For hexane extracts of 100,1000 and $10000 \mathrm{ppm}$, glucose concentration was recorded at $78.41,83.19$ and $453.24 \mathrm{ppm}$, respectively. For aqueous extracts of 100,1000 and $10000 \mathrm{ppm}$, the recorded glucose concentration was $59.53,62.60$ and $373.47 \mathrm{ppm}$, respectively. The same trend of 55.66, 79.22 and $453.29 \mathrm{ppm}$ was recorded at 100, 1000 and $10000 \mathrm{ppm}$ of crude ethanolic extract.

Generally, it can be observed in Table 7 that as the concentration of every solvent extract is increased, glucose level in the sample also increases. The same trend can also be observed in the decocted samples but only in less significant difference. The pure $(4: 0 \mathrm{~m} / \mathrm{v}$ ratio of the sample: water) decocted sample showed to have the highest concentration of glucose among the samples with $453.30 \mathrm{ppm}$ while 5000 ppm crude ethanolic extract has the lowest concentration of glucose with $55.66 \mathrm{ppm}$.

\section{Conclusion}

Alpha-amylase inhibition activity revealed $10000 \mathrm{ppm}$ hexane extract to greatly inhibit the activity of the enzyme. It was then followed by 10000 ppm aqueous and 10000 ppm crude ethanolic extracts respectively. The in vivo method suggests that the fresh extract and the three solvent extracts 
(10000ppm hexane, 10000ppm aqueous, and 10000ppm crude ethanolic extract) of Crescentia cujete Linn. possess hypoglycemic potential and can lower down blood sugar level in Mus musculus. Also, by using the fresh, $1: 1(\mathrm{~m} / \mathrm{v}$ ratio of the sample: water) decocted extract and the three solvent extracts $(10000 \mathrm{ppm}$ hexane, $10000 \mathrm{ppm}$ aqueous, 5000 and $10000 \mathrm{ppm}$ crude ethanolic extract) of Crescentia cujete Linn. before the occurrence of the metabolic disorder diabetes mellitus can help in regulating blood glucose level in the blood.

Results in colorimetric determination of glucose reveals that the fresh and decocted $(4: 0,1: 1$ and 1:3 $\mathrm{m} / \mathrm{v}$ ratio of the sample:water) samples contain relatively high concentration of glucose. Glucose concentrations increase with increasing concentrations of the different extracts.

\section{Acknowledgement}

The researchers would like to thank Dr. Fema M. Abamo, Director of Research, Dr. Otinggue M. Masnar, Vice Chancellor for Research and Extension, Dr. Macapado A. Muslim, former President of Mindanao State University (MSU) System for approving this project and Dr. Habib W. Macaayong, President MSU System, Philippines for funding this research.

\section{References}

Billacura MP and Laciapag GCR (2017). Phytochemical screening, cytotoxicity, antioxidant, and anthelmintic property of the various extracts from crescentia cujete linn. fruit. Science International Lahore, 29(2): 31-35.

Cornely K and Pratt CW (2012). Bioquímica: Comprar Bioquímica Kathleen Cornely. Manual Moderno, Hipódromo, Mexico.

Ekta M (2012). Search for antimicrobial efficacy of certain Indian medicinal plants. International Journal of Pharmaceuticals and Phytopharmacological Research, 4: 187-193.

Honeycutt AA, Boyle JP, Broglio KR, Thompson TJ, Hoerger, TJ, Geiss LS, and Narayan KV (2003). A dynamic Markov model for forecasting diabetes prevalence in the United States through 2050. Health Care Management Science, 6(3): 155164.

Hovorka R, Nodale M, Haidar A, and Wilinska ME (2013). Assessing performance of closed-loop insulin delivery systems by continuous glucose monitoring: drawbacks and way forward. Diabetes Technology and Therapeutics, 15(1): 4-12.

IDF (2013). IDF diabetes atlas. International Diabetes Federation, Brussel, Belgium.

Lenzen S (2008). The mechanisms of alloxan-and streptozotocininduced diabetes. Diabetologia, 51(2): 216-226.

Lima LCDO, Chitarra AB, and Chitarra MIF (2001). Changes in amylase activity starch and sugars contents in mango fruits pulp cv. Tommy Atkins with spongy tissue. Brazilian Archives of Biology and Technology, 44(1): 59-62.

Maher MA, Mataczynski H, Stefaniak HM, and Wilson T (2000). Cranberry juice induces nitric oxide-dependent vasodilation in vitro and its infusion transiently reduces blood pressure in anesthetized rats. Journal of Medicinal Food, 3(3): 141-147.

Miller GL (1959). Use of dinitrosalicylic acid reagent for determination of reducing sugar. Analytical Chemistry, 31(3): 426-428.

NIDDK (2003). US Renal data system: USRDS 2005 annual data report, atlas of end-stage renal disease. National Institute of Diabetes and Digestive and Kidney Diseases, Bethesda, USA. Available online at: https://www.niddk.nih.gov/

Santhakumari P, Prakasam A, and Pugalendi KV (2006). Antihyperglycemic activity of Piper betle leaf on streptozotocin-induced diabetic rats. Journal of Medicinal Food, 9(1): 108-112.

Wang NS (1999). Glucose assay by dinitrosalicylic colorimetric method. Department of Chemical Engineering, University of Maryland, College Park, USA.

WHO (2014). Global health estimates: Deaths by cause, age, sex and country, 2000-2012. World Health Organization, Geneva, Switzerland.

Wild S, Roglic G, Green A, Sicree R, and King H (2004). Global prevalence of diabetes estimates for the year 2000 and projections for 2030. Diabetes Care, 27(5): 1047-1053.

Worthington V (1993). Alpha amylase. In: Worthington V (Ed.), Worthington enzyme manual: 36-41. Worthington Biochemical Corp., Freehold, USA.

$\mathrm{Xu}$ M, Lepisto AJ, and Hendricks RL (2004). CD154 signaling regulates the Th1 response to herpes simplex virus-1 and inflammation in infected corneas. The Journal of Immunology, 173(2): 1232-1239.

Yusuf S, Hawken S, Ôunpuu S, Dans T, Avezum A, Lanas F, and Lisheng L (2004). Effect of potentially modifiable risk factors associated with myocardial infarction in 52 countries (the INTERHEART study): case-control study. The Lancet, 364(9438): 937-952. 